\title{
INVESTIGAÇÕES SOBRE O ENSINO DE GENÉTICA E BIOLOGIA MOLECULAR NO ENSINO MÉDIO BRASILEIRO: REFLEXÕES SOBRE AS PUBLICAÇÕES CIENTÍFICAS
}

\author{
Research on the teaching of Genetics and Molecular \\ Biology in Brazilian High School: \\ reflections about scientific publications
}

\author{
José Romário de Melo ${ }^{1}$ \\ Edinaldo Medeiros Carmo ${ }^{2}$
}

\begin{abstract}
Resumo: Com o objetivo de analisar as publicações relacionadas ao ensino de Genética e Biologia Molecular no Ensino Médio brasileiro, foram consideradas reflexões sobre várias publicações científicas mediante revisão bibliográfica. Foram analisados trabalhos publicados entre 1999 a 2008. A Revista Genética na Escola se destacou quanto à quantidade de artigos publicados. As publicações puderam ser classificadas em diversas categorias, como: análise de livro didático (ALD), histórico (HIS), intrainterdisciplinaridade (IID), metodologia de ensino (MEE), propostas curriculares (PRC) e outros (OUT). Embora compatíveis em quantidade, artigos das categorias ALD, HIS e PRC encontram-se publicados em pouquíssima quantidade. O número de artigos publicados nas categorias IID e MEE soma quase $73 \%$ das publicações encontradas, em relação às demais (as outras categorias juntas somam aproximadamente $27 \%$ ). Este estudo possibilitou considerar que ainda é incipiente a pesquisa voltada ao ensino de Genética e Biologia Molecular, com relação ao Ensino Médio na escola básica brasileira.
\end{abstract}

Palavras-chave: Biologia molecular. Genética. Interdisciplinaridade. Livro didático. Pesquisa bibliográfica.

Abstract: The objective of this work was to analyze the publications related to the teaching of Genetics and Molecular Biology in Brazilian High Schools. We analyzed studies published from 1999 to 2008. The Revista Genética na Escola presents the most published articles. The publications were classified into different categories, such as: textbook analysis (ALD), history (HIS), intra-interdisciplinarity (IID), teaching methodology (MEE), curriculum proposals (PRC) and other (OUT). Equivalent numbers of articles in ALD, HIS and PRC categories are published in very low quantity, however the number of articles published in categories IID and MEE total almost $73 \%$ of the publications found in the others (all other categories together total about 27\%). This study has considered that research dedicated to the teaching of Genetics and Molecular Biology is still in its early stages, related to High Schools in elementary teaching in Brazil.

Keywords: Bibliografic research. Genetics. Interdisciplinarity. Molecular biology. Textbook.

${ }^{1}$ Biólogo, Mestrando em Biotecnologia Vegetal, Universidade Federal de Lavras, MG, Brasil. romariomelo@gmail.com

${ }^{2}$ Biólogo, Doutorando em Educação, Universidade Federal Fluminense; Docente, Laboratório de Ensino, Pesquisa e Extensão em Biologia, Departamento de Ciências Naturais, Universidade Estadual do Sudoeste da Bahia, campus Vitória da Conquista, BA, Brasil. medeirosed@ig.com.br

${ }^{1}$ Av. Boa Vontade, 3454

Ibirapuera - Vitória da Conquista, BA

45.075-205 
Melo, J. R.; Carmo, E. M.

\section{Introdução}

No início da década de 1950, a biologia, como disciplina de Ensino Médio, ainda não dispunha do perfil atual no que tange às divisões de suas subáreas, as quais consistiam apenas em botânica, zoologia e biologia geral. Eram discutidos temas ligados à mineralogia, paleontologia e geologia quando, segundo Freitas e colaboradores apud Krasilchik (2004), os objetivos eram: de valor mais informativo, concernente aos conhecimentos construídos; de valor educativo ou formativo, relacionado ao desenvolvimento do educando; além de apresentar também um valor cultural, visando à contribuição para os grupos sociais dos quais os alunos faziam parte.

As discussões na sala de aula com vistas à construção de um conhecimento consistente, provavelmente não eram realizadas de forma aprofundada acerca de temas mais específicos dentro da biologia - como, por exemplo: anatomia e fisiologia humana, reprodução e dispersão de determinados tipos de vegetais, classificação de grupos e definição do ciclo vital de fungos, dentre outros temas -, de forma que fossem priorizados os conteúdos mais generalizados e que contribuíssem mais para o convívio social do que para o conhecimento científico per se.

Apesar de o ensino de biologia no Brasil, por volta dos anos 50, ainda não ter o perfil que possibilitasse a melhor exploração dos conteúdos e nem um aprofundamento mais específico nas respectivas subáreas como atualmente, tanto pelos alunos quanto pela própria comunidade como um todo, há indícios de que a origem das pesquisas e dos estudos voltados para ensino de ciências no Brasil está relacionada com o movimento de reforma no ensino de ciências, ocorrido no período pós-guerra, entre 1950 e 1960, nos Estados Unidos e na Inglaterra. Tudo indica que a repercussão evidenciada em decorrência desses movimentos, no Brasil, tenha gerado reformas no ensino de ciências no país, as quais duraram até os anos 70 (TEIXEIRA e MEGID-NETO, 2006).

Sob forte influência do ensino europeu, a história natural exerceu sua tendência em tratar de assuntos que considerassem diversos grupos de seres vivos separadamente, estabelecendo suas relações filogenéticas. Esta influência era evidenciada por meio dos livros utilizados na época, mas também pelos vários professores estrangeiros que se fizeram presentes na Educação Superior brasileira. Por volta dos anos 1960, a situação predominante de ensino sofreu intensas modificações no que diz respeito à tradicional divisão da biologia, o que se deu, em parte, por conta da grande explosão do conhecimento biológico que despontara na época. No entanto, os fatores que realmente contribuíram para modificações significativas foram a constatação da importância do ensino de ciências como fundamentalmente relevante enquanto fator de desenvolvimento e a Lei de Diretrizes e Bases da Educação Nacional (LDB) de 1961, a qual proporcionou uma contraposição à existência da centralização das decisões curriculares de responsabilidade da administração federal (KRASILCHIK, 2004).

É possível relacionar as modificações ocorridas no ensino brasileiro, enquanto ensino de ciências, também pela observação da coincidência na época da ocorrência simultânea tanto dos reflexos dos movimentos que trouxeram as inovações para o ensino quanto da gênese dos programas de pesquisa em ensino de ciências no Brasil, no início dos anos 60. Programas esses que constituíram o grande impulso à vontade em ascensão, de professores e pesquisadores, para elaborar materiais de apoio aos docentes de Ensino Fundamental e Médio originalmente nacionais, no intuito de suprir a enorme deficiência que era então evidente, diante da 
disponibilidade que se tinha apenas de materiais inteiramente traduzidos e implantados no Brasil, de origem americana e inglesa, os quais não correspondiam às características da cultura nacional no momento (NARDI, 2005).

O desenvolvimento de pesquisas relacionadas ao ensino de ciências, de um modo geral à Educação em Ciências, é uma atividade que surgiu há aproximadamente 60 anos na esfera mundial. Suas ações foram bastante intensificadas durante a porção final do século XX. Entretanto, no âmbito nacional, as investigações na mesma temática, enquanto movimentos de pesquisa expandiram-se no período inicial da década de 1970, com a discussão desse tema no ambiente da pós-graduação e pelos encontros, simpósios e eventos diversos que, em grande quantidade, agrupavam pesquisadores e outros profissionais atrelados à área (DELIZOICOV, ANGOTTI e PERNAMBUCO, 2002).

A partir de então, vários eventos voltados para o ensino de Ciências foram sendo realizados reunindo professores, alunos, pesquisadores e a quem pudesse interessar os temas, permitindo uma grande interação da comunidade acadêmico-científica. Atualmente, vários são os periódicos, indexados ou não, que disponibilizam os resultados de pesquisas científicas voltadas para a Educação em Ciências no Brasil nas mais diversas áreas (TEIXEIRA e MEGID-NETO, 2006), inclusive a da biologia e também, mais estritamente, da Genética e da Biologia Molecular.

A análise dos conhecimentos e da compreensão da Genética por parte dos jovens estudantes vem sendo muito investigada, assim como pesquisas têm sido realizadas com esse objetivo, atentando para a percepção de problemas propostos que envolvam o uso das novas tecnologias genéticas, em contextos variados, em questões suscitadas nessa área do conhecimento biológico (LEWIS, LEACH e WOOD-ROBINSON, 2000; LEWIS e WOOD-ROBINSON, 2000).

Sobretudo no Ensino Médio, quando o indivíduo está prestes a concluir uma etapa consideravelmente relevante de sua vida na educação básica, é muito importante que haja uma construção do conhecimento de qualidade e, sobretudo, proporcionando uma fundamentação teórico-prática mais consistente. É nesse momento escolar do ensino que os alunos terão uma estruturação preparatória para prosseguir na convivência em sociedade, especialmente no que se refere à sequência dos estudos, de forma que o embasamento construído ao longo do processo de ensino possibilite o pleno aprendizado dos principais fundamentos de Genética, e, atualmente, pode-se incluir a Biologia Molecular, pelos discentes (BRASIL, 2000).

Atualmente, torna-se consensual entre docentes e discentes o fato de haver pouco envolvimento no processo ensino-aprendizagem quando relacionado às dificuldades de aplicabilidade e abstração dos conceitos que são abordados, o que abrange as diversas áreas das Ciências Biológicas. Este aspecto se sobressalta em decorrência de déficit ou, até mesmo, inexistência, em certos momentos, da contextualização de conteúdos (RODRIGUES e MELLO, 2005) remetendo os alunos a uma simples situação de aquisição de conhecimento prévio, superficial ou preparatório para algum evento/prova/concurso, sem propiciar uma possível releitura ou problematização do conteúdo que possibilitasse o desenvolvimento do potencial congênito do indivíduo.

Recentemente, têm sido bastante comuns comentários positivamente expressos por professores relatando sobre experiências bem-sucedidas em se tratando da utilização da Genética Humana em sala de aula, visto que, dessa forma, o aluno torna-se mais interessado 
Melo, J. R.; Carmo, E. M.

devido à maior facilidade de contextualizar o que se ensina (CAMARGO e INFANTE-MALACHIAS, 2007). No entanto, o ensino de biologia, em geral, parece ainda apresentar a ciência completa ou parcialmente desvinculada de relações e/ou aplicações dos conceitos concernentes ao cotidiano dos alunos, sem dar a oportunidade aos mesmos de refletir sobre o seu meio à luz dos novos conhecimentos estruturados em sala de aula (KRASILCHIK, 2004).

Nesse sentido, é relevante observar o impacto das pesquisas que vêm sendo realizadas tendo como objeto de estudo justamente aspectos do ensino de Genética e Biologia Molecular no Ensino Médio. Não basta apenas observar os impactos em relação ao ensino, mas também é proeminente analisar as contribuições que estes trabalhos apresentam no que diz respeito à aprendizagem e, se possível, à transposição dessa aprendizagem para o convívio social dos alunos em seu cotidiano. A desvinculação da ciência com o dia-a-dia, como supracitado, talvez seja efeito exatamente da necessidade de pesquisas que se aprofundem nesta (des) vinculação com a finalidade de, primeiramente, explorar as causas e efeitos dessa relação quase inexistente entre ciência e cotidiano e, posteriormente, determinar possíveis estratégias para solucionar os problemas em questão.

A utilização de ferramentas para tornar o processo de aprendizagem desses conceitos mais efetiva e dinâmica é importante, pois a dinamização dos meios de ensino-aprendizagem pode contribuir para o melhor aprendizado dos estudantes, tanto quando se proporciona o maior envolvimento dos alunos quanto na reestruturação da prática em fuga ao tradicionalismo, este muitas vezes exacerbado, que pode contribuir negativamente no aprendizado dos alunos (PAVAN et al., 1998).

Talvez uma tentativa de contextualizar a Genética, conforme as possibilidades existentes no ambiente escolar, almejando simplificar a condução de experiências práticas, seja uma possível alternativa à construção do conhecimento pela prática. Quem sabe, dessa maneira, seja possível proporcionar maior dinamização na realização de práticas em relação ao estudo com humanos, mediante contextualização com temas discutidos na mídia. Isto contribuiria expressivamente para o desenvolvimento da prática de ensino, gerando uma ótima fonte de discussão, inclusive sem esbarrar ou se contrapor à ética que rege as experiências práticas com animais vivos na escola básica.

Contudo, como preconizado pelos Parâmetros Curriculares Nacionais do Ensino Médio - o PCNEM, deve-se também aproveitar o ensejo da Genética Humana ao permitir que se trabalhe com temas transversais, aparentemente distantes da Biologia, como as questões que envolvem a ética, a política e a sociedade (BRASIL, 2000).

Perante o crescimento das investigações no que tange a Educação em Ciências, constitui aspecto interessante para a área realizar análises das consequências deste crescimento sobre a pesquisa e, portanto, sobre o próprio ensino de ciências desenvolvido nas unidades de ensino no território brasileiro. Estabelecer reflexões sobre os atributos da pesquisa em educação realizada no Brasil é fundamental (TEIXEIRA e MEGID-NETO, 2006), e propicia elevar a qualidade do ensino, uma vez que os resultados dessas reflexões podem servir de embasamento teórico-científico para determinar e/ou apontar mudanças eminentemente importantes para a materialização de um ensino ainda mais sólido.

Diante do preâmbulo apresentado, julgou-se necessária a realização do presente trabalho. Este estudo propõe a apresentação de algumas reflexões sobre os estudos e pesquisas relacionadas ao ensino de Genética e Biologia Molecular no Ensino Médio. 


\section{Metodologia}

O presente estudo foi realizado mediante pesquisa bibliográfica, devido à necessidade de se compreenderem as recentes tendências do ensino de Genética e Biologia Molecular na escola média brasileira. A pesquisa bibliográfica consiste em realizar o levantamento, a seleção, o fichamento e o arquivamento de informações obtidas por meio de documentos de interesse (MARCANTONIO, SANTOS e LEHFELD, 1993).

De modo a orientar os procedimentos seguintes à definição dos objetivos, o plano de trabalho foi sendo construído de maneira a permitir o seu caráter provisório, sofrendo reformulações sucessivas que permitiram o alinhamento do foco deste estudo. A recorrência a textos especializados e o contato com pesquisadores da área, este sobretudo com o objetivo de obter fontes bibliográficas até então não disponíveis on-line ou em bibliotecas de instituições próximas, fizeram parte do planejamento deste estudo.

Em busca de fontes científicas, foram identificados alguns trabalhos publicados em diversos tipos de veiculação da pesquisa científica, desde periódicos especializados até anais de eventos sobre ensino de biologia. Após realizar a identificação do material, procedeu-se com a localização dessas fontes bibliográficas, as quais ocorreram de maneiras como: (i) empréstimos por docentes e (ii) download na rede mundial de computadores (Internet, que nesta pesquisa foi caracterizada apenas como $\mathrm{We}^{3}$ ) em sites que armazenam/disponibilizam os arquivos. Estes sites constituem desde páginas de universidades (bibliotecas on-line e acervos bibliográficos) até páginas pessoais de arquivamento de documentos históricos.

Sucederam-se às etapas de identificação e localização dessas fontes, a leitura do tipo exploratória, a qual, segundo Gil (1996, p. 67), "[...] é uma leitura rápida do material bibliográfico, que tem por objetivo verificar em que medida a obra consultada interessa à pesquisa".

Posteriormente à realização da leitura exploratória, foi coerente seguir com uma leitura seletiva, a qual constituiu etapa determinante para escolha do material que realmente consiste em fonte bibliográfica para a pesquisa. Apesar de ser mais profunda do que a leitura exploratória, não compreende uma leitura definitiva, pois propõe a descoberta de partes principais ainda não identificadas sobre as quais se estrutura o texto. Possibilita, ainda, a compreensão de novas ideias, explicações, discussão e, inclusive, novas concepções da ideia principal do texto (MARCANTONIO, SANTOS e LEAHFELD, 1993; GIL, 1996).

As leituras analíticas e interpretativas foram conduzidas analisando-se os textos como medida definitiva para a continuidade do estudo, tendo a finalidade de ordenar os dados, sumarizando as informações obtidas e permitindo alcançar as respostas almejadas nos objetivos. A leitura analítica constitui uma leitura de natureza crítica, entretanto, observando os preceitos de Gil (1996) foi enfocada, nessa parte do trabalho, a identificação das ideias dos autores procurando isentá-las de julgamentos, adotando posturas que expressaram objetividade, imparcialidade e respeito pelas concepções dos autores.

\footnotetext{
${ }^{3}$ Termo, reduzido em inglês, para referir-se a world wide web, que significa "rede de alcance mundial". Também pode ser expresso como wnw.
} 
Melo, J. R.; Carmo, E. M.

Referindo-se à leitura interpretativa, buscou-se relacionar os resultados defendidos pelos autores com o problema, até então, delimitado. Evitou-se proceder com interpretações aprofundadas do ponto de vista pessoal, na tentativa de eximir a pesquisa de um caráter tendencioso ao subjetivismo exacerbado, validando-a nos parâmetros metodológicos científicos.

Foram tomadas, como objeto de estudo, publicações científicas caracterizadas em quatro categorias de publicações, devido ao periódico de origem: (a) artigos publicados na Revista Genética na Escola (RGE), da Sociedade Brasileira de Genética; (b) artigos publicados na Revista Brasileira de Ensino de Bioquímica e Biologia Molecular (RBEBBM); (c) as publicações dos Anais do I Encontro Nacional de Ensino de Biologia (ENEBIO) e III Encontro Regional de Ensino de Biologia da Regional RJ/ES (EREBIO) - os quais serão referidos apenas como ENEBIO, realizados concomitantemente, no mês de agosto do ano de 2005, na cidade do Rio de Janeiro/RJ; e (d) os artigos encontrados na Web, caracterizados como Artigos Generalizados da Web (AGW).

Os artigos encontrados na Web estavam disponíveis em arquivos de diversos periódicos especializados em educação, como: Revista Ensaio - Pesquisa em educação em ciências; Revista Ciência \& Ensino; Revista Ciência \& Educação; Revista Arquivos do Mudi; Revista Estudos em Avaliação Educacional e nos arquivos dos ENPEC (Encontro Nacional de Pesquisa em Educação em Ciências). Os artigos pertencentes a estes periódicos foram identificados por meio de busca por palavras-chave utilizando diversos instrumentos de busca, especializados em periódicos ou não, como: Google, Google Acadêmico, Scielo (Scientific Eletronic Library Online) e algumas das bases de dados do Portal Periódicos CAPES. A não identificação personalizada desses vários periódicos na pesquisa, a exemplo dos demais supracitados [(a), (b), (c) e (d)], foi devida à pouca quantidade de artigos encontrados em cada um, bem como ao caráter mais generalista das publicações, distanciando-se do tema proposto neste trabalho. Ainda que os periódicos apresentassem um ou poucos trabalhos na temática estudada, o foco não era a educação no Ensino Médio.

\section{Resultados e discussão}

Diante da proposição desta pesquisa, caracterizou-se o perfil das publicações relacionadas ao ensino de Genética e Biologia Molecular no Ensino Médio, demonstrando as reflexões e ideias dos pesquisadores à luz de seus trabalhos publicados.

A caracterização dos dados obtidos mediante levantamento bibliográfico nos periódicos RGE e RBEBBM, anais do ENEBIO e na $W e b$, delimitados como fontes de publicações científicas, demonstraram diferenças entre as quantidades de publicações relacionadas ao ensino de Genética e Biologia Molecular no Ensino Médio (Figura 1).

A RGE se destaca em relação aos demais periódicos, no que tange ao número de artigos, apresentando-se com um maior número de publicações relacionadas ao tema proposto nesta pesquisa. Nesta caracterização, quanto ao número de publicações, há de ser considerado o período compreendido pelas publicações, quando, no geral, adotou-se o período entre as décadas de 1999 e 2008. 


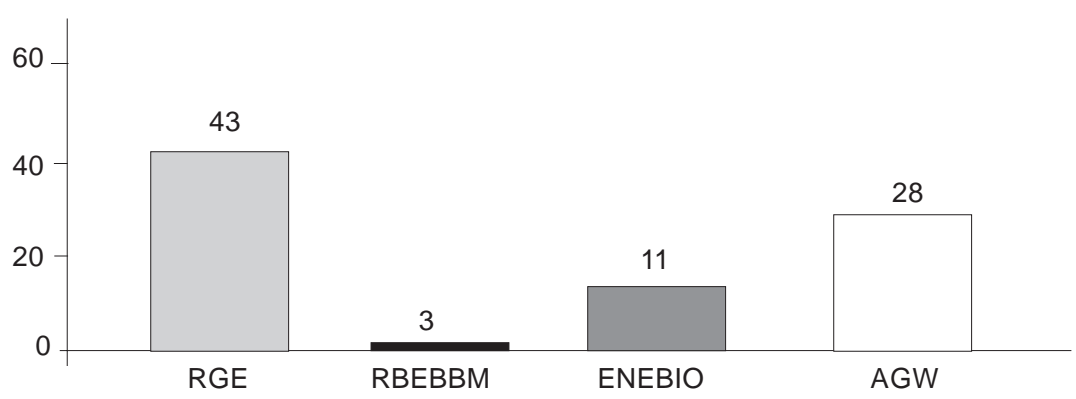

Figura 1. Valores numéricos referentes às quantidades de artigos, identificados por periódicos, que apresentam estudos relacionados ao ensino de Genética e/ou Biologia Molecular no Ensino Médio do Brasil. RGE - Revista Genética na Escola; RBEBBM - Revista Brasileira de Ensino de Bioquímica e Biologia Molecular; ENEBIO - Encontro Nacional de Ensino de Biologia; AGW - Artigos Generalizados da Web.

Entretanto, dentro do período que abrange esta pesquisa, cabe salientar que houve uma heterogeneidade em relação ao tempo em que ocorreram as publicações selecionadas em cada periódico. Mais especificamente, o período compreendido pelas publicações de cada um foi: RGE, 2006 a 2008; RBEBBM, 2001 a 2007; ENEBIO, 2005; e AGW, 1999 a 2007. Alguns fatores explicam essa heterogeneidade evidenciada, como: a origem da RGE no ano de 2006; a não disponibilidade de alguns arquivos (como os anais de outras edições do ENEBIO), e a pouca disponibilidade na $W e b$ de artigos num período menor do que o abrangido pela pesquisa.

Para tanto, julgou-se relevante realizar uma análise proporcional/temporal dos trabalhos selecionados para a pesquisa. Procedendo desta maneira, foi possível representar a proporção de artigos publicados em cada periódico no tempo abrangido por suas publicações. Para efeito de cálculo, considerou-se o período base de uma década. Dessa forma, a equação idealizada foi

$$
\mathrm{P}=\frac{\mathrm{NP} \times 10}{t}
$$

onde $\mathrm{P}=$ Proporção de artigos publicados em uma década; $\mathrm{NP}=$ Número de publicações selecionadas no período compreendido por cada periódico; $10=$ número de anos almejados para efeito de cálculo; e t = período compreendido pelas publicações de cada periódico (Tabela 1).

De acordo com a Tabela 1, torna-se evidente o grande potencial dos periódicos RGE e ENEBIO em publicar trabalhos que mais se relacionam com ideias voltadas ao ensino de Genética e Biologia Molecular. Neste ponto, é importante salientar que os números referentes ao cálculo proporcional para publicações do ENEBIO devem ser tomados como uma proporção virtual. Isto, devido ao fato de esta pesquisa ter analisado os anais de apenas um evento (por indisponibilidade dos demais arquivos), o que não corresponde igualmente às demais fontes de publicações comparadas no cálculo. 
Melo, J. R.; Carmo, E. M.

Tabela 1. Determinação do percentual proporcional de publicações num intervalo de dez anos em relação à quantidade de artigos encontrados em cada periódico, no período abrangido por cada um.

\begin{tabular}{lcccc}
\hline \multicolumn{1}{c}{ FONTE } & RGE & RBEBBM & ENEBIO & AGW \\
\hline No de publicações* $^{*}$ & 43 & 3 & 11 & 27 \\
Período** $_{\text {Proporção (P) }}^{2,5}$ & 172 & 4,3 & 1 & 9 \\
\hline
\end{tabular}

* Quantidade de artigos por periódico; ** Período expresso em anos.

Entretanto, analisando o periódico RBEBBM, foi possível perceber que o mesmo demonstra baixíssima tendência em publicar artigos relacionados ao ensino de Biologia Molecular. Na verdade, a RBEBBM armazena em seu acervo poucos artigos (32 apenas), sendo a grande maioria deles relacionados ao ensino de Bioquímica. Também pode ser considerada baixa a proporção apresentada por AGW, devido ao fato de abranger todos os demais periódicos ao alcance dos sites de busca da $W e b$.

Estima-se, pelos dados coletados e analisados (Figura 1), que o maior número de publicações encontradas na RGE pode ser explicado por algumas variáveis que permitem uma maior disponibilidade de artigos, no periódico, relacionados ao tema estudado. Essas variáveis implicam: ( $($ ) a especialidade da revista no tema Genética, em toda a sua abrangência (Humana e Médica, Vegetal, Animal, Evolutiva e outras áreas afins); (ii) a possibilidade de publicação nas diversas formas de artigos (trabalhos clássicos, metodologias alternativas, atividades práticas e relatos de experiência); e (iii) a promoção, pela Sociedade Brasileira de Genética, de uma maior interação com a sociedade por meio de projetos, como o Genética na Praça, que podem vir a estimular a comunidade acadêmico-docente, envolvida nesse contexto, a produzir e divulgar mais resultados científicos na área (SOCIEDADE BRASILEIRA DE GENÉTICA, 2008).

A caracterização das demais fontes de artigos contempladas pelo trabalho, as quais somam todas juntas a metade das publicações selecionadas para a pesquisa, sugere quão incipiente encontra-se a pesquisa voltada ao ensino de Genética e Biologia Molecular na escola básica brasileira. Sobretudo quanto à Biologia Molecular, que é uma das áreas que mais tem crescido ultimamente, praticamente dominando o campo da biologia nas últimas cinco décadas (MAYR, 1998), as pesquisas/publicações desta nova área voltadas para o ensino somam poucos textos. O periódico RBEBBM disponibiliza, em todo o seu acervo, apenas três artigos científicos apresentando temas relacionados ao ensino dessa área da biologia.

É relevante demonstrar também que esse mesmo periódico abrange publicações desde 2001 até o ano de 2007, porém, a soma total das publicações é de apenas 32 artigos. Isso demonstra a inferioridade do montante de publicações científicas voltadas para o ensino dos demais tipos de pesquisas experimentais/laboratoriais relacionadas à mesma área. Nesse cenário, as pesquisas voltadas ao ensino de Biologia Molecular no Ensino Médio apresentam-se, quantitativamente, em menos de 10\% das publicações do periódico (REVISTA BRASILEIRA DE ENSINO DE BIOQUÍMICA E BIOLOGIA MOLECULAR, 2001).

Ao se analisarem as publicações apresentadas nos anais do ENEBIO, observaram-se muito mais do que os onze trabalhos evidenciados na Figura 1. Porém, todas as outras publicações, não computadas na presente pesquisa, se referiam ao ensino de Genética voltado ao 
Ensino Fundamental e ao Ensino Superior, além de, em alguns casos, os trabalhos terem como foco os cursos de formação de professores.

Com relação aos AGW, as mais diversas formas de publicações foram obtidas, desde revisões de literatura (review) e trajetória histórica até análise de livro didático. Devido à pesquisa desses artigos ter sido realizada por intermédio de instrumentos de busca, foi inevitável a incidência de diversos periódicos, inclusive não especializados para a área, mas que todos juntos foram considerados como um grupo 'generalizado' de artigos.

Numa análise um pouco mais crítica do que a apenas quantitativa, foi possível classificar todo o material em seis categorias diferentes. A categoria pode ser definida como uma classe, um grupo ou o tipo em uma série classificada. A distribuição em categorias foi bastante criteriosa, segundo os princípios de Selltiz et al. (1965), onde a variável que definiu as categorias foi a forma de publicação.

Após realizar a leitura exploratória, procedendo-se com uma leitura seletiva, os artigos foram categorizados em: Análise de Livro Didático (ALD), Histórico (HIS), Intrainterdisciplinar (IIT), Metodologia de Ensino (MEE), Propostas Curriculares (PRC) e Outros (OUT). A categoria considerada como Outros abarca publicações selecionadas que relatam sobre o tema estudado, porém, não se enquadram em nenhuma das outras cinco categorias predefinidas. Aqui é relevante demonstrar o ineditismo deste tipo de classificação, o qual ainda não fora utilizado em nenhuma fonte de pesquisa com o objetivo de classificar os diferentes tipos de publicações relacionadas ao ensino.

Diante dessa classificação, quanto ao tipo de publicação, as categorias definidas apresentaram-se bem próximas entre si com relação ao número de artigos publicados em cada uma das categorias, exceto os trabalhos de Metodologia de Ensino e Intrainterdisciplinaridade. Em análise aos dados tabulados, foi possível perceber que a quantidade de trabalhos dessas duas categorias se destaca bem mais do que as outras quatro categorias (Figura 2).

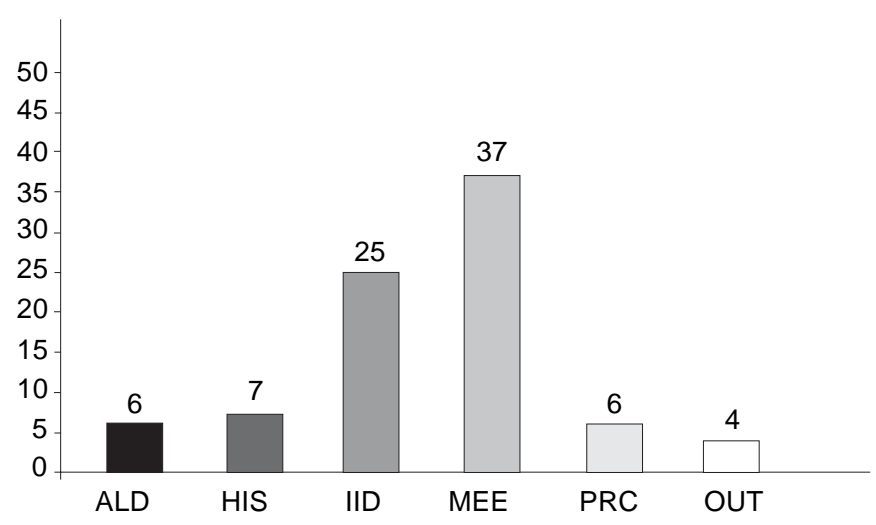

Figura 2. Valores numéricos que apresentam as quantidades de artigos, classificados por categorias (tipo de publicação), relacionados a estudos voltados ao ensino de Genética e/ou Biologia Molecular no Ensino Médio brasileiro. ALD - Análise de Livro Didático; HIS - Histórico; IID - Intra-Interdisciplinaridade; MEE Metodologia de Ensino; PRC - Propostas Curriculares; OUT - Outros. 
Embora compatíveis em quantidade, os artigos das categorias ALD, HIS e PRC encontram-se publicados em pouquíssima quantidade no que se refere às pesquisas relacionadas ao ensino de Genética e Biologia Molecular na escola básica brasileira, sobretudo no Ensino Médio, que é o foco deste trabalho.

$\mathrm{O}$ arquétipo apresentado pelos artigos da categoria ALD no contexto desta pesquisa permite sugerir que, referindo-se à quantidade de publicações, parece não haver maiores preocupações com a fonte de informação que dá suporte aos alunos de Ensino Médio durante o processo de ensino-aprendizagem, o livro didático.

Como evidenciado por Selles e Ferreira (2004), o livro didático é importante fonte de conhecimento, poderoso instrumento para a construção do saber, embasado na seleção e organização de conteúdos. Essas autoras também preconizam a análise dos erros e equívocos evidenciados em vários livros de ciências, os quais podem comprometer em parte ou, mesmo, toda a construção do conhecimento pelos alunos.

Ainda assim, o livro didático não vinha sendo objeto de estudos mais abrangentes e/ ou sistemáticos nos últimos anos, no que tange à comunidade de ensino de ciências (NASCIMENTO e MARTINS, 2005). Entretanto, há sinais de um crescimento no número de pesquisas realizadas, a partir do ano de 2005, objetivando analisar os livros didáticos. Porém, mesmo havendo diversas publicações voltadas à análise de livro didático, como nos anais VI ENPEC (Encontro Nacional de Pesquisadores em Ensino de Ciências), realizado em 2007, são poucas as publicações acerca de análise de livro didático na área de ensino de Genética e Biologia Molecular (Figura 2). Isso comprova a natureza aparentemente (ou, talvez, realmente) estática dos estudos voltados aos veículos de informação utilizados pelos alunos no Ensino Médio brasileiro, ainda mais quando se tem em foco uma área de conhecimento tão complexa como a Genética, ou em grande/recente expansão como a Biologia Molecular.

A importância da pesquisa em educação enfocando o livro didático é destacada, desde a década de 1970, por Fracalanza (1992), contudo, apesar de alguns estudos restritos, no início dos anos 90, nota-se que a ênfase em desenvolver investigações que tomem o livro didático como objeto de estudo permaneceu escassa até a primeira metade da década de 2000.

Como é possível observar também na Figura 2, as pesquisas publicadas, que realizaram investigações relacionadas ao livro didático, encontram-se dentre os tipos de pesquisa que foram publicadas em menor quantidade na década englobada pelo estudo realizado. Além disso, os poucos trabalhos publicados em periódicos e anais de encontros da área de educação, restringem-se à análise de conteúdos, conceitos e abordagens (FRACALANZA, 1992).

É consensual que os livros didáticos, normalmente, têm passado por constantes revisões, contudo ainda é possível se deparar com enganos conceituais, utilização inadequada de imagens e textos verbais que tornam confusa a aprendizagem do tema evidenciado (CAMPOS e LIMA, 2008).

Nesse contexto, se mesmo com muitas análises sobre os livros, em outros temas que não o desta pesquisa, ainda se encontram erros nos livros, não é difícil imaginar quão delicada se torna essa discussão em relação, sobretudo, à Genética e a Biologia Molecular, temas complexos e muito recentes, para os quais foram encontrados poucos trabalhos na categoria ALD. Assim sendo, a probabilidade de erros se eleva muito e isso é preocupante no que tange à educação básica.

Quando a análise foi realizada nos artigos da categoria HIS, não muito diferente da 
categoria discutida anteriormente, as publicações mostraram-se em pequena quantidade (Figura 2). Ao se perceberem as descrições históricas como boas fontes de novos conhecimentos, enaltece-se a importância de haver grande disponibilidade de trabalhos dessa categoria no meio científico-educativo.

Esse tipo de trabalho, quando elaborado e conduzido de forma bem definida e consistente, não só descreve uma trajetória histórica, mas, especialmente, revela informações que abordam aspectos ainda não conhecidos anteriormente (MARTINS, 2000). Isso proporciona o enriquecimento amplo das fontes de conhecimento científico relacionadas às últimas etapas da formação básica, promovidas no Ensino Médio, bem como o estímulo do senso crítico dos alunos que terão acesso a várias fontes de pesquisa.

No entanto, fazendo ainda referência à categoria HIS, dos sete artigos publicados, seis são relacionados ao histórico do DNA. Os estudos abordam o impacto e a importância da elucidação da dupla-hélice, bem como as transformações do conhecimento genético posteriores ao grande feito de Watson e Crick.

Estes trabalhos também caracterizam, historicamente, a trajetória dos vários estudos de pesquisadores predecessores e contemporâneos à definição do modelo proposto em 1953, todos culminando no grande marco histórico da biologia do século XX (SCHEID, FERRARI e DELIZOICOV, 2005). Em suma, os trabalhos preconizam, de forma um tanto implícita no seu discurso, a elucidação da dupla fita como a origem da Biologia Molecular.

Entretanto, entende-se como a grande contribuição para a ocorrência da quase totalidade dos artigos estarem voltados ao histórico da dupla-hélice do DNA, a comemoração do cinquentenário da proposição deste modelo por Watson e Crick. Nesse sentido, a reflexão apresentada por Martins (2000), relatando a importância das descrições históricas para propiciar novos conhecimentos e/ou contribuições de fatos ainda desconhecidos, parece não estar vinculada a esses trabalhos.

A categoria PRC, encontrando-se no mesmo patamar em quantidade de publicações do que as categorias ALD e HIS, apresenta artigos com teor de maior complexidade e reflexão nas discussões. Embora o ponto central das sugestões mediadas nesses trabalhos sejam as propostas de contextualização do conhecimento, são evidentes as tentativas de indicar a incorporação de temas relevantes e atuais no currículo do Ensino Médio.

As proposições que permeiam o contato dos alunos com pesquisas laboratoriais, visitas a exposições temáticas (que podem, por vezes, suprir a inexistência de aulas práticas em determinadas situações), a utilização de textos de divulgação científica como fonte de informação, a inclusão de alguns temas em Genética Humana (projeto genoma e câncer), parecem contribuir amplamente em dois sentidos, para melhorar a prática de ensino e para um aprendizado mais sólido dos alunos.

Nesta categoria, percebeu-se uma forte tendência à associação da Genética com a Biologia Molecular, mas, ao que parece, ainda sem uma intenção propriamente dita de intradisciplinaridade ${ }^{4}$ por parte dos autores. Essa associação se deve aos temas propostos pelos arti-

\footnotetext{
${ }^{4}$ Termo que se refere à associação de dois ou mais temas pertencentes à uma mesma grande área de conhecimento, como, por exemplo: Genética, Citologia, Ecologia (em Biologia) ou Cinemática, Dinâmica, Ondas (em Física). O termo será mais bem especificado no decorrer do texto.
} 
Melo, J. R.; Carmo, E. M.

gos, os quais são dependentes de uma interface entre essas duas ciências para serem ensinados e exemplificados pelos professores e, consequentemente, compreendido pelos alunos.

Com relação à Genética e a Biologia Molecular, a veiculação de notícias diariamente pela mídia e a necessidade de contextualização dos conhecimentos desenvolvidos nos séculos anteriores são os principais arcabouços que norteiam as novas propostas curriculares apresentadas.

Nesta perspectiva, novos termos surgem no dia-a-dia e são utilizados constantemente, sobretudo pela mídia. Terminologias com o objetivo de caracterizar procedimentos e técnicas (Clonagem, Manipulação do DNA, Teste de DNA), ou caracterizar o produto final de alguns destes procedimentos (Alimentos Transgênicos, DNA recombinante, dentre outros), encontram-se disponíveis nas mais variadas formas de comunicação na sociedade.

Porém, especialmente entre os alunos de Ensino Médio, é requerida a existência de um embasamento teórico-reflexivo suficiente quando estes termos, que são explanados dentro do conteúdo relacionado em Genética e Biologia Molecular, abordam aspectos éticos envolvidos na construção do conhecimento científico e tecnológico, que conclamam à reflexão acerca das relações existentes entre a ciência, a tecnologia e a sociedade (BRASIL, 2000).

Como sugerido por Souza, Silva e Dottori (2005) e Nascimento e Alvetti (2006), o conhecimento deve ser proporcionado aos alunos de forma a torná-los cidadãos capazes de se posicionarem criticamente frente a temas atuais e complexos do cotidiano, enquanto conhecimento biológico. A organização de um programa para o Ensino Médio que contemple os conceitos essenciais relacionados à Biologia, que proponha um conhecimento compatível ao veiculado pelos meios de comunicação, é também defendida pelos autores.

Propostas de inclusão de novos tópicos de Genética Humana no currículo, que proporcionem a contextualização, instigando ainda mais os alunos por eles mesmos constituírem o próprio objeto de estudo, culminam numa melhor compreensão dos conceitos desse tema, sobretudo quando há uma atenção especial na abordagem dos tópicos específicos (CAMARGO e INFANTE-MALACHIAS, 2007). Nesse sentido, os autores chamam a atenção para os cuidados em não se explanarem os conteúdos de forma equivocada, sobretudo em relação à herança monogênica e às doenças genéticas em humanos, que quase sempre estão sujeitas à interferência de fatores ambientais.

Partindo para a análise das duas categorias restantes (IID e MEE), é pertinente apresentar um gráfico da percentagem evidenciada desses trabalhos em relação às demais categorias classificadas na pesquisa realizada (Figura 3). Diante da representação, é possível observar a grande diferença entre a quantidade de artigos publicados classificados nessas duas categorias, somando ambas quase $73 \%$ das publicações encontradas, em relação às demais, as quais, todas as quatro categorias, juntas, somam apenas cerca de $27 \%$. 


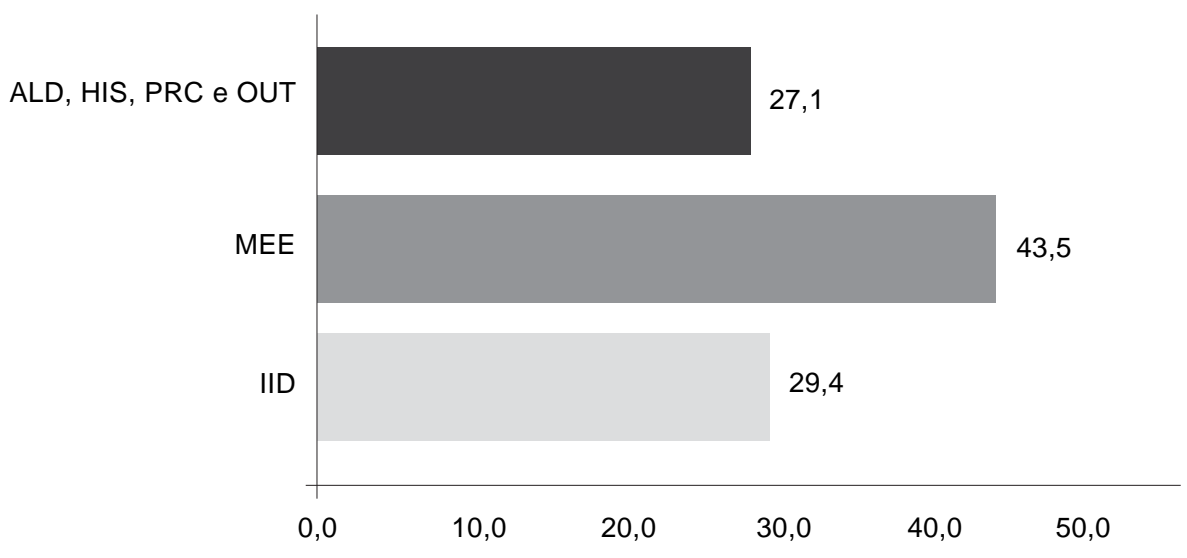

Figura 3. Percentual da quantidade de artigos publicados selecionados para a pesquisa, evidenciando a superioridade das categorias Metodologia de Ensino e Intrainterdisciplinaridade com relação às demais categorias. ALD - Análise de Livro Didático; HIS - Histórico; IID - Intrainterdisciplinaridade; MEE Metodologia de Ensino; PRC - Propostas Curriculares; OUT - Outros.

Analisando primeiramente os artigos IID, antes de uma reflexão mais específica, talvez seja necessário explanar um pouco acerca da definição desta categoria. Preferiu-se unir, numa mesma categoria, tanto os artigos relacionados à intradisciplinaridade quanto os relativos à interdisciplinaridade, numa tentativa de não descaracterizar ou fragmentar a proposta multidisciplinar sugerida pelos Parâmetros Curriculares Nacionais (PCNs), a qual propõe o desenvolvimento do processo de ensino em cada disciplina e no conjunto de disciplinas (BRASIL, 2000).

Considerando também a interdisciplinaridade, baseando-se nas reformas do currículo, da formação de professores e da gestão da educação escolar, Ferretti (2000) considera imprescindível esta interdisciplinaridade para se conseguir superar o arbítrio da proposição de áreas, ou agrupamentos de conteúdos. Equivalente a isto, a contextualização poderá auxiliar o processo ensino-aprendizagem, adequando as disciplinas às características dos alunos e do ambiente socioeconômico.

Foram considerados artigos de intradisciplinaridade as publicações que, de alguma forma, propunham discussões de temas em Genética e/ou Biologia Molecular em associação com outras áreas da biologia como: a ecologia, o melhoramento de plantas, a citologia, a fisiologia, entre outras. Já as publicações de interdisciplinaridade, foram delimitadas por apresentarem um caráter mais pluralista em relação à biologia. A exemplo, foram observadas propostas que abrangiam o tema pesquisado associado à ética, à física, à Eugenia e a outras correntes histórico-filosóficas do conhecimento científico, respaldadas pela História e Filosofia da Ciência. 
Melo, J. R.; Carmo, E. M.

Retomando a análise da categoria IID, percebeu-se claramente a intencionalidade dos estudos em transcenderem os limites da Genética e Biologia Molecular, trazendo discussões bastante reflexivas, consistentes e bem fundamentadas na contribuição para o processo multidisciplinar de ensino-aprendizagem na escola básica. Como referência basal é possível citar a introdução da História da Ciência como fonte de desmistificação da ciência como verdade inquestionável, o que pode ser a origem da dificuldade no entendimento da natureza da atividade científica e fonte de desestímulo para os estudantes (SCHEID e FERRARI, 2006).

O grande interesse pela área da patologia foi notado quando se observou a apresentação de vários estudos, relacionando à Genética, sendo apresentados com base em patossistemas como a Gripe Aviária (DESSEN, 2006), Leucemia (SANTANA-LEMOS, JÁCOMO e SANTOS, 2007) e o Câncer (GUEMBAROVSKI e COLLUS, 2008).

Ao que parece, nesse sentido, a tentativa desses trabalhos é expressar a própria multiplicidade existente entre os temas. Dessa forma, é passível de ser explorada em sala de aula, com o objetivo de melhorar o ensino contemporâneo, a pluralidade da Genética, evitando meras repetições de conteúdos, termos e experiências concretizados no século XX, ou antes. Nessa atmosfera, a interdisciplinaridade e a contextualização, juntas, podem propiciar um redimensionamento por parte dos educadores das experiências dos agentes da escola, de forma que revejam suas práticas e discutam sobre o que ensinam e como ensinam (FERRETTI, 2000).

Numa perspectiva da prática docente, procedendo agora com a análise da classe mais expressiva dentre as publicações selecionadas, a categoria MEE, há uma aparente inclinação para a divulgação de artigos que propõem metodologias de ensino (Figuras 2 e 3). De acordo com os Parâmetros Curriculares Nacionais para o Ensino Médio, se há alguma unanimidade relativa ao plano de conceito dos educadores na área de Ciências, é quanto à necessidade de se incorporarem e implementarem métodos de aprendizado ativos e interativos (BRASIL, 2000).

O elaborar/proporcionar métodos alternativos contribui para sanar uma das principais dificuldades dos alunos no aprendizado, tanto da Genética quanto da Biologia Molecular, que é a compreensão dos conceitos e o entendimento sobre a estrutura das moléculas basais da vida (SOARES, PINTO e ROCHA, 2005). Sarmieri e Justina apud Justina e Ferla (2006), discutindo acerca das necessidades formativas assinaladas por professores de biologia, apontam a proposição de recursos didáticos como uma das principais alternativas, visando facilitar o processo ensino e aprendizagem.

Todavia, apesar de não ser o foco desta pesquisa analisar os periódicos, mas sim os artigos, ante os dados, percebeu-se a importância em demonstrar a expressiva diferença na quantidade de artigos da categoria MEE publicados no periódico RGE (Figura 4). Também é relevante informar que a rigorosidade adotada no processo de categorização foi criteriosa, especialmente pela existência de artigos, dentre os selecionados, que apresentavam metodologias de ensino simultaneamente às propostas de intradisciplinaridade. 


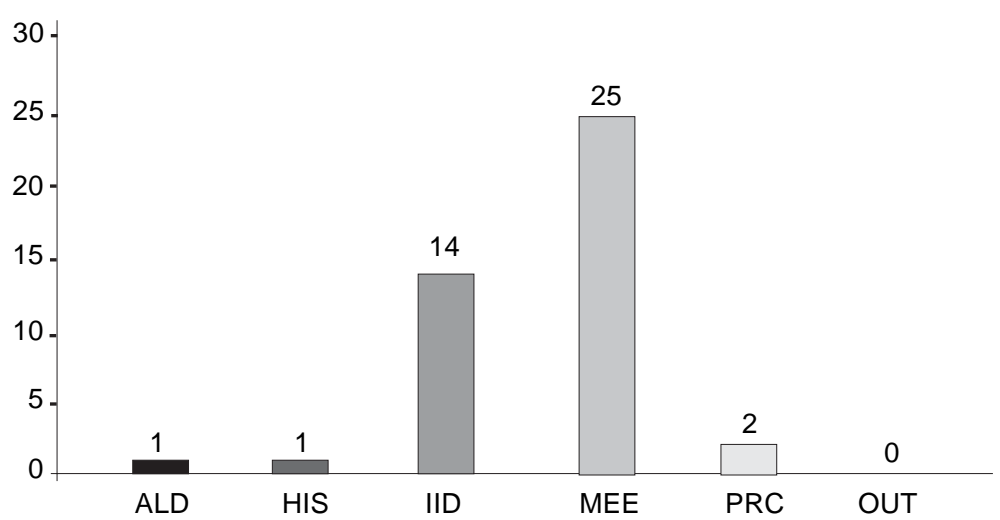

Figura 4. Distribuição do número de publicações, por categorias, no periódico Revista Genética na Escola. ALD - Análise de Livro Didático; HIS - Histórico; IID - Intrainterdisciplinaridade; MEE - Metodologia de Ensino; PRC - Propostas Curriculares; OUT - Outros.

Dentre as principais justificativas que fundamentam as premissas dos trabalhos, encontram-se a busca pela melhor aprendizagem dos alunos mediante a utilização do lúdico (jogos e dramatização), simulação de investigação científica e a utilização de multimídias e softwares no processo de ensino. Além dessas estratégias, ainda se fizeram presentes nos artigos - agora não só considerando os trabalhos da RGE -, discussões teóricas sobre os novos conceitos de gene, utilização de artigos de jornal e atividades em grupo, embasadas na transposição didática ${ }^{5}$.

Devido ao extenso vocabulário compreendido pela área de Genética, e igualmente sua complexidade e especificidade, somando-se a estes fatores a dificuldade para a compreensão e diferenciação dos conceitos envolvidos, Salim et al. (2007) propuseram a possibilidade de utilização até do baralho como recurso didático. Nessa atividade, bem como em outras envolvendo grupos de alunos sem haver um caráter individual, é evidente a tentativa da valorização de atividades coletivas.

Estas atividades coletivas, segundo os PCNs, podem propiciar a discussão e a elaboração conjunta de ideias e de práticas, nas quais o aluno possa ser desafiado pelo jogo do conhecimento, e não somente pelos outros integrantes da atividade (BRASIL, 2000).

É válido ressaltar os vários trabalhos que trouxeram propostas muito bem elaboradas de metodologias que proporcionam o contato dos alunos de Ensino Médio com técnicas avançadas relacionadas à Biologia Molecular (que acabam refletindo, também, nos conceitos

\footnotetext{
${ }^{5}$ É um instrumento por meio do qual analisamos o movimento do saber sábio (aquele que os cientistas descobrem) para o saber a ensinar (aquele que está nos livros didáticos) e por intermédio deste, ao saber ensinado (aquele que realmente acontece em sala de aula).
} 
de Genética). As sugestões ocorrem mediante a elaboração de materiais, geralmente para aulas práticas e em grupo, que simulam a execução de técnicas avançadas utilizadas em laboratórios de alta tecnologia.

Exemplos desses métodos foram detectados nos artigos em diversas formas. Dentre as mais complexas e instigadoras estão: a utilização de gel de amido, em substituição ao gel de agarose, para a execução de eletroforese de ácidos nucléicos, proporcionando o barateamento da técnica e permitindo a fácil execução da mesma (MARTINEZ e PAIVA, 2008), e o mapeamento cromossômico, utilizando fotomicrografias de fungos (Sordaria fimicola) recombinantes (MORI, PEREIRA e VILELA, 2008).

Entretanto, atividades mais simples, passíveis de serem realizadas com a utilização de materiais de papelaria, também foram sugeridas, a exemplo da amplificação do DNA por PCR (Polymerase Chain Reaction), utilizando-se recurso didático alternativo, confeccionado com materiais de papelaria (BONETTI, VIEIRA e SIQUIEROLI, 2006); e do mapeamento gênico, mediante o uso de figuras impressas em papel ofício. Nesta última, a intenção é a representação de um condomínio e seus moradores, simulando os vários componentes das células envolvidos na atividade gênica, bem como na sua identificação no genoma (CAPELLI e NASCIMENTO, 2008).

Demonstra-se evidente a contribuição das metodologias apresentadas pelos artigos da categoria MEE, sobretudo no sentido de amplificar a acessibilidade ao conhecimento, pelos alunos, de processos biológicos não explorados usualmente em salas de aula. As sugestões, na grande maioria das vezes, permitem aos professores gerarem materiais e modelos didáticos de baixo custo e realizarem os métodos na própria sala de aula, o que proporciona superlativas agilidade e eficiência no processo de ensino.

Ainda sobre o processo ensino-aprendizagem, proposições como as desses artigos contribuem significativamente para as diferentes formas de ensinar. Estas, sendo o reflexo da ação como modo de agir, de acordo com Pimenta e Anastasiou (2002), ultrapassam as práticas didáticas usuais do ensino, ampliando o que, anteriormente, talvez, poderia existir apenas como uma sequência de ações individuais docente. Nesse contexto, utilizar um modelo, como a construção de uma estrutura que pode ser utilizada como referência, ou até mesmo como uma imagem, que permite a materialização de uma ideia ou de um conceito existente na mente dos alunos, de acordo com Giordan e Vecchi (1996), pode contribuir para que os mesmos se tornem diretamente assimiláveis.

\section{Considerações finais}

Diante da pesquisa realizada, é possível considerar que ainda é incipiente o número de publicações voltadas ao ensino de Genética e Biologia Molecular, com relação ao Ensino Médio na escola básica brasileira. Sobretudo no que diz respeito à Biologia Molecular, mesmo por ser uma área ainda recente da biologia, foi possível observar que esta vem sendo incorporada às práticas docentes no Ensino Médio, o que, no futuro, provavelmente, pode vir a fazer parte do currículo escolar.

É necessária a condução de um maior número de investigações acerca das abordagens de ensino da Genética e Biologia Molecular nas escolas de Ensino Médio do Brasil. Também 
Investigações sobre o ensino de Genética ...

é relevante disponibilizar à comunidade a leitura, análise e posicionamento crítico resultantes destas pesquisas, bem como reflexões diversas acerca da temática estudada, o que contribui para o enriquecimento substancial do processo ensino-aprendizagem.

\section{Referências}

BONETTI, A. M.; VIEIRA, C. U.; SIQUIEROLI, A. C. S. Amplificação de DNA (Simulação de Polymerase Chain Reaction-PCR) atividade para sala de aula. Genética na Escola, Ribeirão Preto, v. 1, n. 2, p. 63-65, 2006.

BRASIL. Ministério da Educação e Cultura. Secretaria de Educação Básica. Parâmetros Curriculares Nacionais do Ensino Médio: Ciências da Natureza, Matemática e suas Tecnologias. Secretaria de Educação Média e Tecnológica. Brasília: MEC/SEMTEC, 2000.

CAMARGO, S. S.; INFANTE-MALACHIAS, M. E. A genética humana no Ensino Médio: algumas propostas. Genética na Escola, Ribeirão Preto, v. 2, n. 1, p. 14-16, 2007.

CAMPOS, A. F.; LIMA, E. N. Ciclo do nitrogênio: abordagem em livros didáticos de ciências do Ensino fundamental. Investigações em Ensino de Ciências, Porto Alegre, v. 13, n. 1, p. 35-44, 2008.

CAPELLI, L. P.; NASCIMENTO, R. M. P. O mapa da mina: entendendo o mapeamento gênico. Genética na Escola, Ribeirão Preto, v. 3, p. 11-18, 2008.

DELIZOICOV, D.; ANGOTTI, J. A.; PERNAMBUCO, M. M. Ensino de ciências: fundamentos e métodos. São Paulo: Cortez, 2002.

DESSEN, E. M. B. Gripe aviária: seguindo as pegadas de um novo vírus. Genética na Escola, Ribeirão Preto, v. 1, n. 1, p. 4-7, 2006.

FERRETTI, C. J. Mudanças em sistemas estaduais de ensino em face das reformas no Ensino Médio e no Ensino Técnico. Educação \& Sociedade, Campinas, v. 21, n. 70, p. 8099, 2000.

FRACALANZA, H. O que sabemos sobre os livros didáticos para o ensino de ciências no Brasil. 1992. 293f. Tese (Doutorado em Educação) - Faculdade de Educação, Universidade Estadual de Campinas, Campinas, 1992.

GIL, A. C. Como elaborar projetos de pesquisa. 3. ed. São Paulo: Atlas, 1996.

GIORDAN, A.; VECCHI, G. As origens do saber: das concepções dos aprendentes aos conceitos científicos. 3. ed. Porto Alegre: Artes Médicas, 1996.

GUEMBAROVSKI, R. L.; COLLUS, I. M. S. Câncer: uma doença genética. Genética na Escola, Ribeirão Preto, v. 3, n. 1, p. 4-7, 2008.

JUSTINA, L. A. D.; FERLA, M. R. A utilização de modelos didáticos no ensino de genética - exemplo de representação de compactação do DNA eucarioto. Arquivos da Apadec, Maringá, v. 10, n. 2, p. 35-40, 2006. 
Melo, J. R.; Carmo, E. M.

KRASILCHIK, M. Prática de ensino de biologia. 4. ed. São Paulo: Edusp, 2004.

LEWIS, J.; WOOD-ROBINSON, C. Genes, chro-mosomes, cell division and inheritance do students see any relationship? International Journal of Science Education, London, v. 22 , n. 2 , p. $177-195,2000$.

; LEACH, J.; WOOD-ROBINSON, C. What's in a cell? - young people's understanding of the genetic relationship between cells, within an individual. Journal of Biological Education, London, v. 34, n. 3, p. 129-132, 2000.

MARCANTONIO, A. T.; SANTOS, M. M.; LEHFELD, N. A. S. Elaboração e divulgação do trabalho científico. 1. ed. São Paulo: Atlas, 1993.

MARTINEZ, E. R. M.; PAIVA, L. R. S. Eletoforese de ácidos nucléicos: uma prática para o ensino de genética. Genética na Escola, Ribeirão Preto, v. 3, n. 1, p. 43-48, 2008.

MARTINS, R. A. Que tipo de História da Ciência esperamos ter nas próximas décadas? Episteme, Porto Alegre, v. 10, n. 1, p. 39-56, 2000.

MAYR, E. O desenvolvimento do pensamento biológico: diversidade, evolução e herança. Trad. Ivo Martinazzo. Brasília: UnB, 1998.

MORI, L.; PEREIRA, M. A. Q. R.; VILELA, C. R. Mapeamento cromossômico no fungo Sordaria fimicola. Genética na Escola, Ribeirão Preto, v. 3, n. 1, p. 19-29, 2008.

NARDI, R. A educação em ciências, a pesquisa em ensino de ciências e a formação de professores no Brasil. In: ROSA, M. I. P. (Ed.). Formar: encontros e trajetórias com professores de ciências. São Paulo: Escrituras, 2005. p. 89-141.

NASCIMENTO, T. G.; ALVETTT, M. A. S. Temas científicos contemporâneos no ensino de biologia e física. Ciência \& Ensino, Campinas, v. 1, n. 1, p. 29-39, 2006.

.; MARTINS, I. O texto de genética no livro didático de ciências: uma análise etórica crítica. Investigações em Ensino de Ciências, Porto Alegre, v. 10, n. 2, p. 255-278, 2005.

PAVAN, O. H. O. et al. Evoluindo genética: um jogo educativo. 1. ed. Campinas: Ed. Unicamp, 1998.

PIMENTA, S. G.; ANASTASIOU, L. G. C. Docência no ensino superior. 1. ed. São Paulo: Cortez, 2002.

REVISTA BRASILEIRA DE ENSINO DE BIOQUÍMICA E BIOLOGIA

MOLECULAR. Campinas: Sociedade Brasileira de Bioquímica e Biologia Molecular, 2001. Disponível em: <http://www.sbbq.org.br/revista/index.php>. Acesso em: 25 mar. 2008.

RODRIGUES, C. C.; MELLO, M. L. A prática no ensino de genética e biologia molecular: desenvolvimento de recursos didáticos para o Ensino Médio, 2005. Disponível em: <http://www.pucminas.br/seminarioprograd/iv_seminario/pdfs/

puc_prat_ens_gen.pdf $>$. Acesso em: 20 abr. 2008.

SALIM, D. C. et al. O baralho como ferramenta no ensino de genética. Genética na

Escola, Ribeirão Preto, v. 2, n. 1, p. 6-9, 2007. 
Investigações sobre o ensino de Genética ...

SANTANA-LEMOS, B. A. A.; JÁCOMO, R. H.; SANTOS, G. A. S. Leucemias: misteriosas e temidas, mas não invencíveis! Genética na Escola, Ribeirão Preto, v. 2, n. 2, p. 1-3, 2007.

SCHEID, N. M. J.; FERRARI, N. A história da ciência como aliada no ensino de genética. Genética na Escola, Ribeirão Preto, v. 1, n. 1, p. 17-18, 2006.

.; FERRARI, N.; DELIZOICOV, D. A construção coletiva do conhecimento científico sobre a estrutura do DNA. Ciência \& Educação, Bauru, v. 11, n. 2, p. 223-233, 2005.

SELLES, S. E.; FERREIRA, M. S. Influências histórico-culturais nas representações sobre as estações do ano em livros didáticos de ciências. Ciência \& Educação, Bauru, v. 10, n. 1, p. 101-110, 2004.

SELLTIZ, J. D. et al. Métodos de pesquisa nas relações sociais. 1. ed. São Paulo: Herder, 1965.

SOARES, K. C.; PINTO, M. C.; ROCHA, M. O. Cada lócus por si mesmo: por onde andam esses genes? Genética na sala de aula: estratégias de ensino e aprendizagem. Rio de Janeiro: PROMED/UFRJ, 2005. Disponível em: <http://www.ccmn.ufrj.br/curso/ trabalhos/PDF/biologia-trabalhos/genetica/genetica4.pdf>. Acesso em: 18 abr. 2008.

SOCIEDADE BRASILEIRA DE GENÉTICA. 2008. Disponível em: <http:// www.sbg.org.br/GeneticaEscola2/web/index.htm>. Acesso em: 18 mai 2008.

SOUZA, E. O. S.; SILVA, E. S.; DOTTORI, S. S. Biologia para o Ensino Médio. Projeto de Reorientação Curricular para o Estado do Rio de Janeiro. Biologia, 2005.

Disponível em: <http://omnis.if.ufrj.br/ curriculo/11-exatas-biologia.pdf > . Acesso em: 05 mar. 2008.

TEIXEIRA, P. M. M.; MEGID-NETO, J. Investigando a pesquisa educacional: um estudo enfocando dissertações e teses sobre o ensino de biologia no Brasil. Investigações em Ensino de Ciências, Porto Alegre, v. 11, n. 2, p. 261-282, 2006.

Artigo recebido em setembro de 2009 e aceito em novembro de 2009. 